\title{
Morfologia polínica de algumas espécies dos gêneros Neoregelia L.B.Sm. e Nidularium Lem. (Bromeliaceae) do Estado de São Paulo, Brasil ${ }^{1}$
}

\author{
Bianca Alsina Moreira ${ }^{2,3}$, Maria Amélia Vitorino da Cruz-Barros² e Maria das Graças Lapa Wanderley²
}

Recebido em 12/11/2003. Aceito em 13/07/2004

\begin{abstract}
RESUMO -(Morfologia polínica de algumas espécies dos gêneros Neoregelia L.B. Sm. e Nidularium Lem. (Bromeliaceae) do Estado de São Paulo, Brasil). É apresentado o estudo dos grãos de pólen das espécies Neoregelia laevis (Mez) L.B. Sm., Nidularium angustibracteatum Leme, N. billbergioides (Schult. f.) L.B. Sm., N. burchellii (Baker) Mez, N. meeanum Leme, Wand. \& Mollo, N. procerum Lindm. e N. seidelii L.B. Sm. \& Reitz, visando contribuir um melhor posicionamento taxonômico da subfamília Bromelioideae. Os grãos de pólen foram acetolisados, medidos, descritos e fotografados sob microscopia óptica e, também, em microscopia eletrônica de varredura. A morfologia polínica revelou grãos de pólen 2(3)-porados, exina semitectada, reticulada, raro foveolada, muros simplescolumelados a duplicolumelados. Com base nos dados polínicos quantitativos e qualitativos verificou-se a grande afinidade entre Neoregelia laevis e Nidularium burchellii, N. billbergioides e N. seidelii (subgênero Canistropis), e entre Nidularium procerum com Nidularium meeanum e $N$. angustibracteatum (subgênero Nidularium). Nidularium billbergioides apresentou muros duplicolumelados, destacando-se, nesse aspecto, das outras espécies.
\end{abstract}

Palavras-chave: Bromeliaceae, palinotaxonomia, Nidularium, Neoregelia

ABSTRACT -(Pollen morphology of some species of the genera Neoregelia L.B. Sm. and Nidularium Lem. (Bromeliaceae) at São Paulo State, Brazil). This paper presents a study of the pollen grains of Neoregelia laevis (Mez) L.B. Sm., Nidularium angustibracteatum Leme, N. billbergioides (Schult. f.) L.B. Sm., N. burchellii (Baker) Mez, N. meeanum Leme, Wand. \& Mollo, N. procerum Lindm. and N. seidelii L.B. Sm. \& Reitz, to contribute for evaluating their taxonomic position within the subfamily Bromelioideae. The pollen grains were acetolyzed, measured, described and photographed under light microscope, and scanning electron microscope. The pollen grains are 2(3)-porate, semitectate, reticulate, rarely foveolate. Based on analysis of the morphology and measurements of pollen grains we verified a strict relationship among Neoregelia laevis and Nidularium burchellii, N. billbergioides and N. seidelii (subgenus Canistropsis), and among Nidularium procerum with Nidularium meeanum and $N$. angustibracteatum (subgenus Nidularium). Nidularium billbergioides, with its duplicolumellate walls differs from all others species.

Key words: Bromeliaceae, palynotaxonomy, Nidularium, Neoregelia

\section{Introdução}

Bromeliaceae, com cerca de 54 gêneros e 3.000 espécies (Luther \& Sieff 1998), é uma família quase exclusivamente neotropical e de ocorrência em praticamente todos os ecossistemas brasileiros.

A morfologia e a ultraestrutura polínica têm oferecido importantes dados para a taxonomia de Bromeliaceae, auxiliando na melhor delimitação genérica e de espécies muito semelhantes, como pode ser observado nos trabalhos desenvolvidos por Ehler \& Schill (1973), Erdtman \& Praglowski (1974), Wanderley \& Melhem (1991) e Halbritter (1992). Entretanto, o conhecimento dos caracteres polínicos nesta família ainda é pequeno, apesar destes constituírem uma importante ferramenta na taxonomia da família.

A frágil circunscrição de alguns gêneros em Bromeliaceae tem levado os autores a se posicionarem diferentemente como, por exemplo, no caso de Nidularium e Neoregelia, gêneros muito relacionados e bem representados no Brasil. Esses gêneros caracterizam-se, principalmente, pela inflorescência nidular, envolvida por um invólucro de brácteas primárias, geralmente com escapo curto, ou mesmo, praticamente ausente, sendo freqüente a presença de rizoma ou estolão. Distinguem-se entre si pelo fato de Nidularium possuir brácteas primárias geralmente vistosas, inflorescência ramificada, flores geralmente sésseis e pétalas com ápice, freqüentemente arredondado e

\footnotetext{
Parte da Dissertação de Mestrado da primeira Autora

Instituto de Botânica, C. Postal 4005, CEP 01061-970, São Paulo, SP, Brasil

3 Autor para correspondência: biancamoreira@yahoo.com
} 
cuculado em Nidularium, enquanto Neoregelia apresenta brácteas, em geral, pouco vistosas, inflorescência não ramificada e corimbosa, flores pediceladas e pétalas com ápice agudo ou acuminado, ereto ou reflexo (Mez 1891-1894; Smith \& Downs 1979).

A morfologia polínica foi utilizada na sistemática de Bromeliaceae a partir de Mez (1891-1894; 1896). Mez (1934-1935), com base no padrão de abertura dos grãos de pólen, reconheceu para Bromeliaceae, três subfamílias: Pticairnoideae, Tillandsioideae e Bromelioideae. Esse autor considerou, entre outros caracteres, a morfologia polínica na separação das subfamílias e das tribos de Bromelioideae. As duas primeiras subfamílias foram consideradas estenopolínicas com grãos de pólen monocolpados e, Bromelioideae, euripolínica com diversos tipos de aberturas, até grãos de pólen inaperturados. Para a subfamília Bromelioideae, Mez (1934-1935) propôs as seguintes tribos: Integrae, com grãos de pólen inaperturados; Poratae, com grãos de pólen porados e Sulcatae, com grãos de pólen sulcados.

A partir da década de 1970 foram realizados vários trabalhos utilizando microscopia óptica e de varredura no estudo da morfologia polínica de espécies de Bromeliaceae. Entre eles, destaca-se o de Ehler \& Schill (1973) que estudaram os grãos de pólen de 217 espécies incluídas em 39 gêneros, através da microscopia óptica e eletrônica de varredura, confirmando que a subfamília Bromelioideae é euripolínica e as subfamílias Pticairnoideae e Tillandsioideae, estenopolínicas. Os autores classificaram os grãos de pólen de Bromeliaceae em três tipos e vários subtipos, de acordo com o padrão de abertura e a escultura da exina. Os gêneros Neoregelia e Nidularium foram classificados no Tipo Aechmea, subtipo Neoregelia farinosa, que inclui os gêneros de Bromelioideae da tribo Poratae, caracterizados pelos grãos de pólen 2-porados a pantoporados com lumens multibaculados e muros salientes (com cristas).

Erdtman \& Praglowski (1974) investigaram os grãos de pólen de 125 espécies incluídas em 40 gêneros da família Bromeliaceae, as quais foram subdivididas em dois grupos, um com grãos de pólen monocolpados e outro com grãos de pólen porados. Dez espécies de Neoregelia e Nidularium foram estudadas e classificadas no segundo grupo, com grãos de pólen 2-porados, exina reticulada, exceto Nidularium burchellii Mez, com grãos de pólen 2-3-porados.

Wanderley \& Melhem (1991) estudaram os grãos de pólen de 30 espécies distribuídas em nove gêneros da família Bromeliaceae da Reserva do Parque
Estadual das Fontes do Ipiranga, São Paulo, incluindo nesse estudo uma espécie de Nidularium, do qual foi utilizado, sempre que possível, material vivo, posteriormente, incorporado ao herbário. As autoras chamaram a atenção para os cuidados na escolha da metodologia de preparação dos grãos de pólen em Bromeliaceae, em função da deformação provocada durante o processo de acetólise, utilizando a acetólise láctica (ACLAC) de Raynal \& Raynal (1971), com adaptações ao grupo, método que permite observar, no microscópio, a saída do conteúdo protoplasmático antes que o grão de pólen se deforme.

Halbritter (1992) estudou 31 gêneros e 338 espécies de Bromeliaceae sob microscopia eletrônica de varredura, dando uma visão geral, especialmente, da morfologia da abertura sem, entretanto, apresentar medidas dos grãos de pólen e descrições das espécies. Foram estudadas 14 espécies de Neoregelia e seis de Nidularium, incluindo N. billbergioides (Schult. f.) L.B. Sm. e N. burchellii Baker estudadas, também, no presente trabalho.

Tardivo \& Rodrigues (1998) investigaram a morfologia dos grãos de pólen, sob microscopia eletrônica de varredura, dos gêneros Nidularium e Canistrum do Estado do Paraná. Os autores descreveram, para N. billbergioides (Schult. f.) L.B. Sm. e $N$. gracile Tardivo (sinônimo de $N$. procerum Lindm.), grãos de pólen mais arredondados que o padrão, tradicionalmente, descrito para o gênero e com aberturas menores.

Halbritter \& Till (1998) apresentaram um estudo, baseado em microscopia eletrônica de varredura, da morfologia polínica de um complexo de gêneros afins, incluindo Aechmea, Canistrum, Neoregelia, Nidularium (incluindo Canistropsis) e Witrockia. Concluíram que duas espécies do gênero Nidularium subg. Nidularium possuíam grãos de pólen que não podiam ser diferenciados de Canistropsis (subgênero de Nidularium) e que as mesmas não se adequavam às características de Nidularium. Em relação às espécies de Neoregelia subgênero Neoregelia os autores concluíram que os grãos de pólen eram idênticos aos de Canistropsis quanto às dimensões do grão de pólen e dos poros e à exina reticulada, porém, comentaram que as aberturas eram freqüentemente cobertas, em parte, por fragmentos de exina. A exina era, geralmente, reticulada com lumens arredondados em Canistropsis e Neoregelia e poligonais em Nidularium.

Dando continuidade ao estudo do gênero Nidularium para a Flora do Estado de São Paulo, o 
presente trabalho teve como principal proposta reconhecer os padrões da morfologia polínica de algumas espécies desse gênero, procurando elucidar os problemas taxonômicos entre espécies afins e tornar mais clara a circunscrição do gênero. Foram estudadas seis espécies de Nidularium, sendo três do subgênero Canistropsis e três do subgênero Nidularium, além de uma espécie de Neoregelia, gênero muito relacionado ao subgênero Canistropsis.

\section{Material e métodos}

Foram analisados os grãos de pólen de sete espécies, uma do gênero Neoregelia e seis do gênero Nidularium. O material estudado é procedente do Estado de São Paulo e foi obtido da coleção viva do Instituto de Botânica, de material obtido em expedições recentes ou em alguns casos, de material dos herbários Maria Eneyda P. Kaufmann Fidalgo (SP) e Bradeanum (HB).

No presente trabalho optou-se pela classificação proposta por Mez (1896) seguida também por Smith \& Downs (1979), Pereira \& Leme (1986) e Wanderley $\&$ Moreira (2000), na qual Canistropsis é tratado como subgênero de Nidularium.

Para cada espécie determinou-se um espécime como "padrão", que é citado abaixo seguido de asterisco. Procurou-se estudar outros espécimes de cada espécie, denominados "materiais de comparação". Segue a relação do material estudado:

Neoregelia L.B. Sm. subgênero Neoregelia: Neoregelia laevis (Mez) L.B. Sm. - BRASIL. São Paulo: Cubatão, IV/1999, S. Kanashiro s.n. (SP 367797)*.

Nidularium Lem. subgênero Canistropsis Mez: Nidularium billbergioides (Schult. f.) L.B. Sm. BRASIL. São Paulo: Tapiraí, 27/II/1997, S.L. Proença et al. 164 (SP)*; Sete Barras, 10/V/1993, S. Kanashiro et al. 10 (SP). Nidularium burchellii (Baker) Mez - Itanhaém, 13/VII/1956, M. Kuhlmanm 3901 (SP)*; Ubatuba, 9/VIII/1995, E.M.C. Leme et al. 3169 (HB). Nidularium seidelii L.B. Sm. \& Reitz Ubatuba-Taubaté, 11/VIII/1995, E.M.C. Leme, Wand. \& Mollo 3195 (HB)*; Sete Barras, s.d., M.G.L. Wanderley s.n. (Coleção viva IBt 110).

Nidularium Lem. subgênero Nidularium: Nidularium angustibracteatum Leme - BRASIL. São Paulo: Pariquera-Açú, 12/IX/2000, B.A. Moreira et al. 219 (SP)*; Cunha, s.d., S. Buzato et al. 59333 (SP). Nidularium meeanum Leme, et al. - Cananéia, X/1999, M.G.L. Wanderley et al. 2321 (SP)*;
1/XI/2000, B.A. Moreira et al. 224 (SP); X/1995, M. Kirizawa 1521 (SP). Nidularium procerum Lindm. - Iguape, I/2000, M.V. Alves \& E. Anunciação 1797 (SP)*; Bananal, E. Catharino s.n. (Coleção viva IBt 487).

O material polínico coletado nas coleções vivas e no campo foi fixado em ácido acético glacial. De todos os materiais foram retiradas duas a três anteras de cada flor, cujos grãos de pólen foram submetidos às técnicas de preparação adequadas, conforme descritas a seguir. Na análise dos grãos de pólen em microscopia óptica foi utilizado o método de acetólise láctica (ACLAC) de Raynal \& Raynal (1971) a 60\% que não provocou deformação polínica. Para o preparo das lâminas foram utilizadas esferas de massa de modelar com menos de $1 \mathrm{~mm}$ de diâmetro, postas entre a lâmina e a lamínula para evitar compressão dos grãos de pólen com parede frágil (Reitsma 1969). Os grãos de pólen foram medidos e fotomicrografados até três dias após sua preparação (Wanderley \& Melhem 1991). No material padrão foram obtidas medidas dos diâmetros equatoriais maior e menor, em vista polar, e diâmetros polar e equatorial, em vista equatorial, de 25 grãos de pólen tomados ao acaso. Foram feitos tratamentos estatísticos e dada a faixa de variação, sendo calculados: média aritmética $(\bar{x})$, desvio padrão da média $\left(\mathrm{s}_{\overline{\mathrm{x}}}\right)$ desvio padrão da amostra (s) e o coeficiente de variabilidade $(\mathrm{V})$. As comparações das médias foram feitas através da análise do intervalo de confiança (IC) a 95\% (Vieira 1981). Para as medidas dos demais caracteres como aberturas e paredes dos grãos de pólen, bem como dos diâmetros dos materiais de comparação, foi calculada, somente, a média aritmética de 10 medidas.

Os grãos de pólen acetolisados e preparados para exame em microscopia óptica foram fotografados digitalmente, com fotomicroscópio Olympus modelo BX50, acoplado a uma câmara de vídeo Sony, e microcomputador (PC) empregando o software Image Pro-plus, versão 3.0 para Windows. Essas imagens foram processadas eletronicamente, para montagem das figuras.

Para análise em microscopia eletrônica de varredura (MEV), os grãos de pólen foram desidratados em série alcoólica crescente e depositados num suporte ("stub"), metailzados com ouro e observados em microscópio Philips XL Series XL 20, S/W, ver. 5.21, sendo tiradas eletromicrografias.

Nos grãos de pólen 2-porados que possuem uma face plana e outra convexa, foi difícil distinguir a vista polar da equatorial; nestes casos a polaridade foi 
definida por comparação seguindo a relação apresentada por M.G.L Wanderley (comunic. pessoal).

Para o gênero Neoregelia, a descrição dos grãos de pólen foi baseada na espécie que representa o gênero. Nos subgêneros Canistropsis e Nidularium, de Nidularium representados por mais de um táxon, foi apresentada a descrição polínica geral com base nos caracteres morfopolínicos das espécies.

A terminologia morfológica adotada foi a de Punt et al. (1999).

\section{Resultados}

Neoregelia L.B. Sm.

Subgênero Neoregelia: Neoregelia laevis (Mez) L.B. Sm. (Fig. 1-3, Tab. 1-3).

Grãos de pólen de tamanho médio; âmbito elíptico; equatorialmente, apresentam contorno plano de um lado e nitidamente convexo do outro; 2-porados, poros pequenos, quase circulares; exina semitectada, reticulada, heterobrocada, com malhas menores junto aos poros, lumens geralmente arredondados, muros estreitos, esparsamente perfurados, simplescolumelados; sexina mais espessa que a nexina.

Nidularium Lem.

Subgênero Canistropsis: Nidularium billbergioides (Schult. f.) L.B. Sm. (Fig. 4-6); Nidularium burchellii (Baker) Mez (Fig. 7-10); Nidularium seidelii L.B. Sm. \& Reitz (Fig. 11-14). Tab. 1-4.

Grãos de pólen de tamanho médio a grande; âmbito elíptico ( $N$. seidelii) a ovalado, equatorialmente apresentam contorno plano de um lado a nitidamente convexo do outro; 2-(3)-porados, poros pequenos, quase circulares; exina semitectada, reticulada, heterobrocada, com malhas menores junto aos poros; muros esparsamente perfurados, simplescolumelados a duplicolumelados ( $N$. billbergioides); sexina mais espessa que a nexina.

Registra-se em Nidularium billbergioides 96\% de grãos de pólen 2-porados e 4\% de grãos de pólen 3-porados; em N. burchellii $90 \%$ de grãos de pólen 2-porados e 10\% de grãos de pólen 3-porados.

Sob MEV, observa-se exina reticulada com raras perfurações em $N$. burchellii e $N$. seidelii e foveolada com perfurações esparsas em $N$. billbergioides (Fig. 6).

Subgênero Nidularium: Nidularium angustibracteatum Leme (Fig. 15-18); N. meeanum Leme, et al. (Fig.
19-25), N. procerum Lindm. (Fig. 26-27). Tab. 1-4.

Grãos de pólen de tamanho médio a grande; âmbito subretangular; 2-porados, poros grandes; exina semitectada, reticulada, heterobrocada, com malhas menores junto aos poros; muros estreitos, simplescolumelados, esparsamente perfurados; sexina mais espessa que a nexina.

Sob MEV observa-se que os retículos possuem lumens de contornos variáveis e muros ondulados, devido às columelas proeminentes nos pontos de interseção dos muros.

A tabela 1 mostra as características morfopolínicas e as tabelas 2-4, os dados qualitativos.

Analisando-se na tabela 2 o IC a 95\% do diâmetro equatorial em vista polar, observa-se que:

a. Neoregelia laevis e Nidularium burchellii não se separam significativamente entre si, distinguindo-se porém, das demais espécies; o mesmo ocorre com Nidularium meeanum e Nidularium procerum;

b. Nidularium angustibracteatum, Nidularium billbergioides e Nidularium seidelii, não se separam entre si quanto ao tamanho, mas diferenciam-se, significativamente, das demais espécies.

As espécies estudadas possuem medidas dos poros entre $7,12 \times 4,39 \mu \mathrm{m}$ (Neoregelia laevis) e $42,53 \times 36,80 \mu \mathrm{m}$ (Nidularium meeanum) conforme se observa na tabela 3 . Já as maiores e menores dimensões dos grãos de pólen são encontradas em Nidularium meeanum e Neoregelia laevis, respectivamente.

Naquelas espécies em que foi possível analisar espécimes de comparação, a relação entre as medidas dos materiais padrão e de comparação foram as seguintes:

a. em Nidularium billbergioides (S. Kanashiro 10) todos os diâmetros se encontram dentro da faixa de variação da espécie do material padrão;

b. em Nidularium angustibracrteatum (S. Buzato 59333) as dimensões dos grãos de pólen são bem distintas e estão fora da faixa de variação;

c. em Nidularium procerum (E. Catharino s.n.) e N. seidelii (M.G.L. Wanderley s.n.) somente os valores dos diâmetros equatoriais maiores em vista polar estão dentro da faixa de variação do material padrão; d. em Nidularium meeanum o espécime M. Kirizawa 1521 apresenta apenas os valores do diâmetro equatorial fora da faixa de variação do material padrão, ao passo que o espécime B.A. Moreira 224 apresenta apenas os valores do diâmetro polar em vista equatorial dentro da faixa de variação do material padrão. 


\section{Discussão}

Os resultados obtidos pelo estudo da morfologia polínica mostraram a formação de dois grupos nitidamente separados pelo tipo de abertura e escultura da exina. O primeiro grupo apresenta grãos de pólen com aberturas pequenas (menores que $10 \mu \mathrm{m}$ ) e retículos heterobrocados, com columelas não proeminentes nos pontos de interseção dos muros, incluindo Neoregelia laevis, Nidularium billbergioides, $N$. burchellii e $N$. seidelii. As espécies deste grupo enquadram-se no Tipo III - Aechmea,
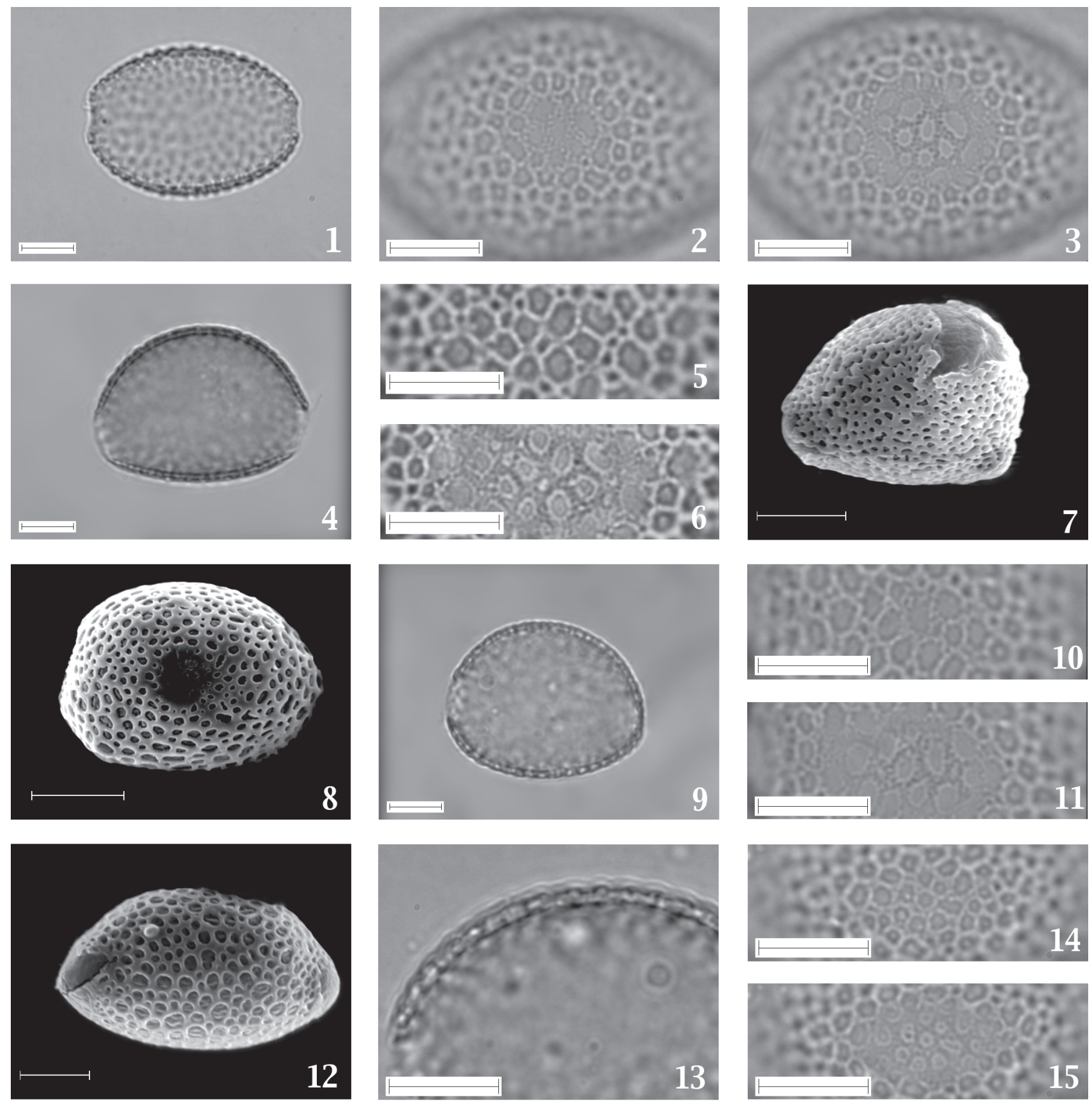

Figuras 1-3. Neoregelia laevis (Mez) L.B. Sm. 1. Vista polar do grão de pólen; 2-3. Análise de LO. Figuras 4-7. Nidularium billbergioides (Schult. f.) L.B. Sm. 4. Vista equatorial do grão de pólen; 5-6. Análise de LO; 7. Eletromicrografia evidenciando aspecto geral do grão de pólen 3-porado. Figuras 8-11. Nidularium burchellii Baker. 8. Eletromicrografia evidenciando o poro; 9. Vista equatorial do grão de pólen; 10-11. Análise do LO. Figuras 12-15. Nidularium seidelii L.B. Sm. \& Reitz. 12. Eletromicrografia evidenciando o aspecto geral do grão de pólen; 13. Corte óptico; 14-15. Análise de L.O. Escala: $10 \mu \mathrm{m}$. 
Tabela 1. Caracteres morfológicos dos grãos de pólen de Neoregelia L.B. Sm. e Nidularium Lem. CP= columelas proeminentes nos pontos de interseção dos muros; $\mathrm{E}=$ elíptico; $\mathrm{G}$ = grande; $\mathrm{M}$ = médio; $\mathrm{P}=$ pequeno; $\mathrm{O}=$ ovalado; $\mathrm{SCP}=$ sem columelas proeminentes nos pontos de interseção dos muros; $\mathrm{SR}=$ subretangular.

\begin{tabular}{|c|c|c|c|c|c|}
\hline \multirow[t]{2}{*}{ Táxon } & \multirow[t]{2}{*}{ Tamanho } & \multirow[t]{2}{*}{ Âmbito } & \multicolumn{2}{|c|}{ Poros } & \multirow{2}{*}{$\begin{array}{c}\text { Caracterização do retículo } \\
(\mathrm{MEV})\end{array}$} \\
\hline & & & Número & Tamanho & \\
\hline \multicolumn{6}{|l|}{$\begin{array}{l}\text { Gênero Neoregelia } \\
\text { subgênero Neoregelia }\end{array}$} \\
\hline Neoregelia laevis & M & $\mathrm{E}$ & 2 & $\mathrm{P}$ & $\mathrm{SCP}$ \\
\hline \multicolumn{6}{|l|}{$\begin{array}{l}\text { Gênero Nidularium } \\
\text { subgênero Canistropsis }\end{array}$} \\
\hline Nidularium billbergioides & $M-G$ & $\mathrm{O}$ & $2-(3)$ & $\mathrm{P}$ & $\mathrm{SCP}$ \\
\hline Nidularium burchellii & M & $\mathrm{O}$ & $2-(3)$ & & \\
\hline $\begin{array}{c}\text { Nidularium seidelii } \\
\text { subgênero Nidularium }\end{array}$ & $M-G$ & $\mathrm{E}$ & 2 & $\mathrm{P}$ & $\mathrm{SCP}$ \\
\hline Nidularium angustibracteatum & $M-G$ & SR & 2 & $\mathrm{G}$ & $\mathrm{CP}$ \\
\hline Nidularium meeanum & $M-G$ & SR & 2 & G & $\mathrm{CP}$ \\
\hline Nidularium procerum & $M-G$ & SR & 2 & G & $\mathrm{CP}$ \\
\hline
\end{tabular}

subtipo Neoregelia farinosa, proposto por Ehler \& Schill (1973), com grãos de pólen 2-porados, exina reticulada e muros com saliências (cristas). Esses autores estudaram $N$. billbergioides, sendo que nos resultados do presente trabalho, não foi confirmada a presença de saliências (cristas) nos muros. Halbritter \& Till (1998) estudaram Nidularium billbergioides, N. burchellii, N. seidelii (Canistropsis, como gênero) e Neoregelia laevis, mostrando padrão semelhante ao que foi observado no presente estudo.

Tardivo \& Rodrigues (1998) comentaram que os grãos de pólen de Nidularium billbergioides e $N$. gracile Tardivo, espécie que foi sinonimizada com $N$. procerum, são mais arredondados que os grãos de pólen do gênero Nidularium e com aberturas mais estreitas, entretanto não apresentaram medidas. Os grãos de pólen aqui estudados apresentam aberturas pequenas em $N$. billbergioides e aberturas grandes em $N$. procerum.

No segundo grupo estão incluídas as seguintes espécies: Nidularium angustibracteatum, $N$. meeanum e $N$. procerum. Essas espécies apresentam grandes aberturas que são típicas do gênero Nidularium subgênero Nidularium, já apontadas por Erdtman \& Praglowski (1974), Wanderley \& Melhem (1991), Halbritter (1992) e Halbritter \& Till (1998). Grãos de pólen muito semelhantes quanto a esse padrão de abertura foram referidos para outros gêneros como Quesnelia, Aechmea e Neoregelia (Ehler \& Schill 1973; Wanderley \& Melhem 1991). Da mesma maneira que as espécies do primeiro grupo, estas também foram incluídas por Ehler \& Schill (1973) no Tipo polínico III - Aechmea, subtipo Neoregelia farinosa. Estes autores também estudaram Nidularium procerum, encontrando dados de ornamentação semelhantes aos aqui obtidos. Nidularium meeanum e $N$. procerum apresentaram grãos de pólen ligeiramente maiores e apesar de possuírem duas aberturas como as espécies do primeiro grupo, estas são bem distintas.

Grãos de pólen com aberturas grandes, como os de Nidularium subg. Nidularium, tendem a apresentar maior grau de deformação. Isso ficou bem evidente no estudo dos grãos de pólen de Nidularium innocentii Lem., realizado por Wanderley \& Melhem (1991). As duas grandes aberturas, típicas do subgênero Nidularium, se expandem durante a acetólise na ocasião da saída do conteúdo protoplasmático, causando a deformação do grão de pólen. Para o presente estudo, seguiu-se a recomendação daquelas autoras, utilizando a técnica de acetólise láctica. Foi fundamental o estudo em microscopia óptica complementado com a eletrônica de varredura, permitindo observar melhor os padrões de escultura e a forma das aberturas.

O presente trabalho, além de fornecer dados quanto à morfologia polínica, permitiu analisar melhor alguns problemas encontrados na delimitação de espécies afins, como no caso de Nidularium angustibracteatum, $N$. meeanum e $N$. procerum. As diferenças entre essas espécies são muito tênues, estando mais relacionadas às dimensões da planta, à largura da lâmina foliar e ao número de flores por inflorescência. Analisando-se as populações destas 
Tabela 2. Medidas dos diâmetros dos grãos de pólen das espécies do gênero Neoregelia L.B. Sm. e Nidularium Lem.

\begin{tabular}{|c|c|c|c|c|c|}
\hline Táxons & $\mathrm{x} \pm \mathrm{s}_{\bar{x}}(\mu \mathrm{m})$ & $\mathrm{s}(\mu \mathrm{m})$ & $\mathrm{V}(\%)$ & $\mathrm{FV}(\mu \mathrm{m})$ & $\mathrm{IC}(\mu \mathrm{m})$ \\
\hline \multicolumn{6}{|l|}{ Neoregelia } \\
\hline \multicolumn{6}{|l|}{ Neoregelia laevis } \\
\hline \multicolumn{6}{|l|}{ Vista Equatorial } \\
\hline Diâmetro equatorial & $44,77 \pm 0,49$ & 1,90 & 4,25 & $41,63-49,00$ & $43,99-45,55$ \\
\hline Diâmetro polar & $33,27 \pm 0,29$ & 1,43 & 4,29 & $31,37-36,25$ & $32,68-33,85$ \\
\hline \multicolumn{6}{|l|}{ Vista Polar } \\
\hline Diâmetro equatorial Maior & $44,35 \pm 0,42$ & 2,08 & 4,69 & $40,25-48,38$ & $43,49-45,20$ \\
\hline Diâmetro equatorial menor & $35,99 \pm 0,49$ & 2,44 & 6,79 & $32,75-45,25$ & $34,98-37,00$ \\
\hline \multicolumn{6}{|l|}{ Nidularium } \\
\hline \multicolumn{6}{|l|}{ subgênero Canistropsis } \\
\hline \multicolumn{6}{|l|}{ Nidularium billbergioides } \\
\hline \multicolumn{6}{|l|}{ Vista Equatorial } \\
\hline Diâmetro equatorial & $47,66 \pm 0,49$ & 2,44 & 5,11 & $44,00-52,50$ & $46,66-48,66$ \\
\hline Diâmetro polar & $36,45 \pm 0,52$ & 2,60 & 7,13 & $31,87-41,88$ & $35,38-37,52$ \\
\hline \multicolumn{6}{|l|}{ Vista Polar } \\
\hline Diâmetro equatorial Maior & $46,89 \pm 0,56$ & 2,81 & 5,99 & $41,25-52,25$ & $45,73-48,05$ \\
\hline Diâmetro equatorial menor & $38,01 \pm 0,42$ & 2,11 & 5,55 & $31,87-41,88$ & $37,14-38,88$ \\
\hline \multicolumn{6}{|l|}{ Nidularium burchellii } \\
\hline \multicolumn{6}{|l|}{ Vista Equatorial } \\
\hline Diâmetro equatorial & $44,48 \pm 0,45$ & 2,23 & 5,01 & $39,75-48,13$ & $43,56-45,39$ \\
\hline Diâmetro polar & $35,73 \pm 0,43$ & 2,17 & 6,06 & $32,88-39,63$ & $34,84-36,62$ \\
\hline \multicolumn{6}{|l|}{ Vista Polar } \\
\hline Diâmetro equatorial Maior & $42,82 \pm 0,58$ & 2,89 & 6,74 & $38,63-49,25$ & $41,63-44,01$ \\
\hline Diâmetro equatorial menor & $38,43 \pm 0,42$ & 2,12 & 5,52 & $34,50-42,38$ & $37,56-39,30$ \\
\hline \multicolumn{6}{|l|}{ Nidularium seidelii } \\
\hline \multicolumn{6}{|l|}{ Vista Equatorial } \\
\hline Diâmetro equatorial & $50,01 \pm 0,50$ & 2,51 & 5,02 & $46,00-56,88$ & $48,97-51,04$ \\
\hline Diâmetro polar & $36,52 \pm 0,44$ & 2,20 & 6,02 & $32,88-41,25$ & $35,61-37,43$ \\
\hline \multicolumn{6}{|l|}{ Vista Polar } \\
\hline Diâmetro equatorial Maior & $48,65 \pm 0,56$ & 2,81 & 5,78 & $42,88-52,50$ & $47,49-49,80$ \\
\hline Diâmetro equatorial menor & $38,71 \pm 0,33$ & 1,66 & 4,29 & $35,75-41,63$ & $38,03-39,39$ \\
\hline \multicolumn{6}{|l|}{ subgênero Nidularium } \\
\hline \multicolumn{6}{|l|}{ Nidularium angustibracteatum } \\
\hline \multicolumn{6}{|l|}{ Vista Equatorial } \\
\hline Diâmetro equatorial & $50,12 \pm 0,51$ & 2,55 & 5,10 & $45,75-53,87$ & $49,07-51,17$ \\
\hline Diâmetro polar & $35,63 \pm 0,30$ & 1,48 & 4,17 & $32,13-38,13$ & $35,01-36,24$ \\
\hline Vista Polar & & & & & \\
\hline Diâmetro equatorial Maior & $48,17 \pm 0,60$ & 3,01 & 6,24 & $42,00-53,25$ & $46,93-49,40$ \\
\hline Diâmetro equatorial menor & $37,03 \pm 0,27$ & 1,37 & 3,70 & $34,00-40,25$ & $36,46-37,60$ \\
\hline Nidularium meeanum & & & & & \\
\hline Vista Equatorial & & & & & \\
\hline Diâmetro equatorial & $56,65 \pm 0,70$ & 3,50 & 6,18 & $51,50-64,25$ & $51,21-58,09$ \\
\hline Diâmetro polar & $42,24 \pm 0,45$ & 2,25 & 5,32 & $38,13-45,50$ & $41,31-43,16$ \\
\hline Vista Polar & & & & & \\
\hline Diâmetro equatorial Maior & $54,71 \pm 0,70$ & 3,49 & 6,37 & $45,63-60,00$ & $53,27-56,15$ \\
\hline Diâmetro equatorial menor & $47,78 \pm 0,38$ & 1,90 & 3,98 & $44,63-50,88$ & $46,99-48,56$ \\
\hline Nidularium procerum & & & & & \\
\hline Vista Equatorial & & & & & \\
\hline Diâmetro equatorial & $54,33 \pm 0,87$ & 4,35 & 8,02 & $47,88-62,63$ & $52,53-56,12$ \\
\hline Diâmetro polar & $43,28 \pm 1,14$ & 5,72 & 13,21 & $36,63-62,25$ & $40,92-45,63$ \\
\hline Vista Polar & & & & & \\
\hline Diâmetro equatorial Maior & $55,07 \pm 0,89$ & 4,43 & 8,04 & $45,75-62,75$ & $53,25-56,89$ \\
\hline Diâmetro equatorial menor & $52,03 \pm 0,77$ & 3,84 & 7,38 & $45,25-59,00$ & $50,45-53,62$ \\
\hline
\end{tabular}


Tabela 3. Medidas, em $\mu \mathrm{m}$, das aberturas e espessura da exina das espécies dos gêneros Neoregelia L.B. Sm. e Nidularium Lem.

\begin{tabular}{|c|c|c|c|c|}
\hline Táxons & Aberturas & Exina & Sexina & Nexina \\
\hline \multicolumn{5}{|l|}{$\begin{array}{l}\text { Neoregelia } \\
\text { subgênero Neoregelia }\end{array}$} \\
\hline Neoregelia laevis & $7,12 \times 4,39$ & 4,65 & 3,25 & 1,40 \\
\hline \multicolumn{5}{|l|}{$\begin{array}{l}\text { Nidularium } \\
\text { subgênero Canistropsis }\end{array}$} \\
\hline Nidularium billbergioides & $9,78 \times 8,26$ & 4,33 & 2,75 & 1,00 \\
\hline Nidularium burchellii & $8,28 \times 7,17$ & 4,28 & 3,17 & 1,15 \\
\hline Nidularium seidelii & $9,83 \times 6,91$ & 4,37 & 3,05 & 1,35 \\
\hline \multicolumn{5}{|l|}{ subgênero Nidularium } \\
\hline Nidularium angustibracteatum & $33,76 \times 31,98$ & 4,67 & 2,80 & 1,12 \\
\hline Nidularium meeanum & $42,53 \times 36,80$ & 4,33 & 2,83 & 1,30 \\
\hline Nidularium procerum & $32,84 \times 26,14$ & 4,37 & 3,08 & 0,80 \\
\hline
\end{tabular}

espécies no campo é possível reconhecê-las, entretanto, alguns indivíduos intermediários podem ser facilmente confundidos, tornando-se muito mais difícil o reconhecimento das mesmas no material de herbário. Nidularium procerum apresenta grande variação quanto ao tamanho da planta; as plantas menores se aproximam de $N$. meeanum, espécie que compartilha o mesmo ambiente na Ilha do Cardoso, em São Paulo. Foram analisadas populações de $N$. angustibracteatum e $N$. procerum provenientes de Pariquera-açú (São Paulo) verificando-se que além de ambas possuírem época de floração semelhante, diferenciam-se apenas pela largura das folhas e das brácteas.

O tamanho do grão de pólen sugere o reconhecimento de duas classes, com base na variação dos diâmetros, nos quais as espécies com menor dimensão do grão de pólen e dos poros foram as espécies dos subgêneros Neoregelia e Canistropsis, enquanto o grão de pólen e os poros de maior dimensão pertencem ao subgênero Nidularium. As espécies Neoregelia laevis e Nidularium burchellii apresentam intervalo de confiança a 95\% do diâmetro equatorial maior, em vista polar, relativamente menor que as demais espécies, enquanto Nidularium procerum e $N$. meeanum apresentam intervalos de confiança significativamente maiores. No entanto, a interpretação desse carácter demonstrou alguma subjetividade já que em Nidularium billbergioides, $N$. seidelii (subgênero Canistropsis) e $N$. angustibracteatum (subgênero Nidularium) ocorreu sobreposição dos intervalos de confiança.

A análise dos grãos de pólen de Nidularium angustibracteatum, $N$. meeanum e $N$. procerum reforçou a grande afinidade entre elas, pois possuem o mesmo tipo de âmbito retangular, poros grandes (maiores que $20 \mu \mathrm{m}$ ) e columelas proeminentes nos pontos de interseção dos muros. As pequenas

Tabela 4. Medidas dos diâmetros dos grãos de pólen dos materiais de comparação de Nidularium Lem. DE = diâmetro equatorial; $\mathrm{DP}=$ diâmetro polar.

\begin{tabular}{|c|c|c|c|c|}
\hline \multirow[t]{2}{*}{ Táxons } & \multicolumn{2}{|c|}{ Vista Equatorial } & \multicolumn{2}{|c|}{ Vista Polar } \\
\hline & $\mathrm{DE}$ & DP & DE maior & DE menor \\
\hline \multicolumn{5}{|l|}{$\begin{array}{l}\text { Nidularium } \\
\text { subgênero Canistropsis }\end{array}$} \\
\hline Nidularium billbergioides (S. Kanashiro 10) & 46,70 & 34,92 & 47,73 & 36,46 \\
\hline Nidularium burchellii (E.M.C. Leme 3169) & 43,29 & 31,51 & 41,94 & 33,10 \\
\hline $\begin{array}{l}\text { Nidularium seidelii (M.G.L. Wanderley s.n.) } \\
\text { subgênero Nidularium }\end{array}$ & 45,29 & 31,05 & 44,96 & 33,81 \\
\hline Nidularium angustibracteatum (S. Buzato 59333) & 56,13 & 43,73 & 54,90 & 43,56 \\
\hline Nidularium meeanum (M. Kirizawa 1521) & 41,64 & 42,24 & 54,71 & 47,78 \\
\hline Nidularium meeanum (B.A. Moreira 224) & 46,84 & 40,35 & 41,19 & 43,01 \\
\hline Nidularium procerum (E. Catharino s.n.) & 46,71 & 32,80 & 45,79 & 35,80 \\
\hline
\end{tabular}


diferenças nas dimensões dos grãos de pólen não são diagnósticas pois, às vezes, há sobreposição das medidas. Com base nesses resultados e considerando a grande semelhança entre esses táxons, levanta-se a possibilidade dos mesmos constituirem um único táxon polimórfico.
Com base nos dados polínicos, na morfologia da inflorescência e da flor, verificou-se a grande afinidade entre Neoregelia laevis e Nidularium burchellii e entre $N$. billbergioides e $N$. seidelii. As duas últimas espécies, posicionadas no subgênero Nidularium (Smith \& Downs 1979), parecem mais relacionadas
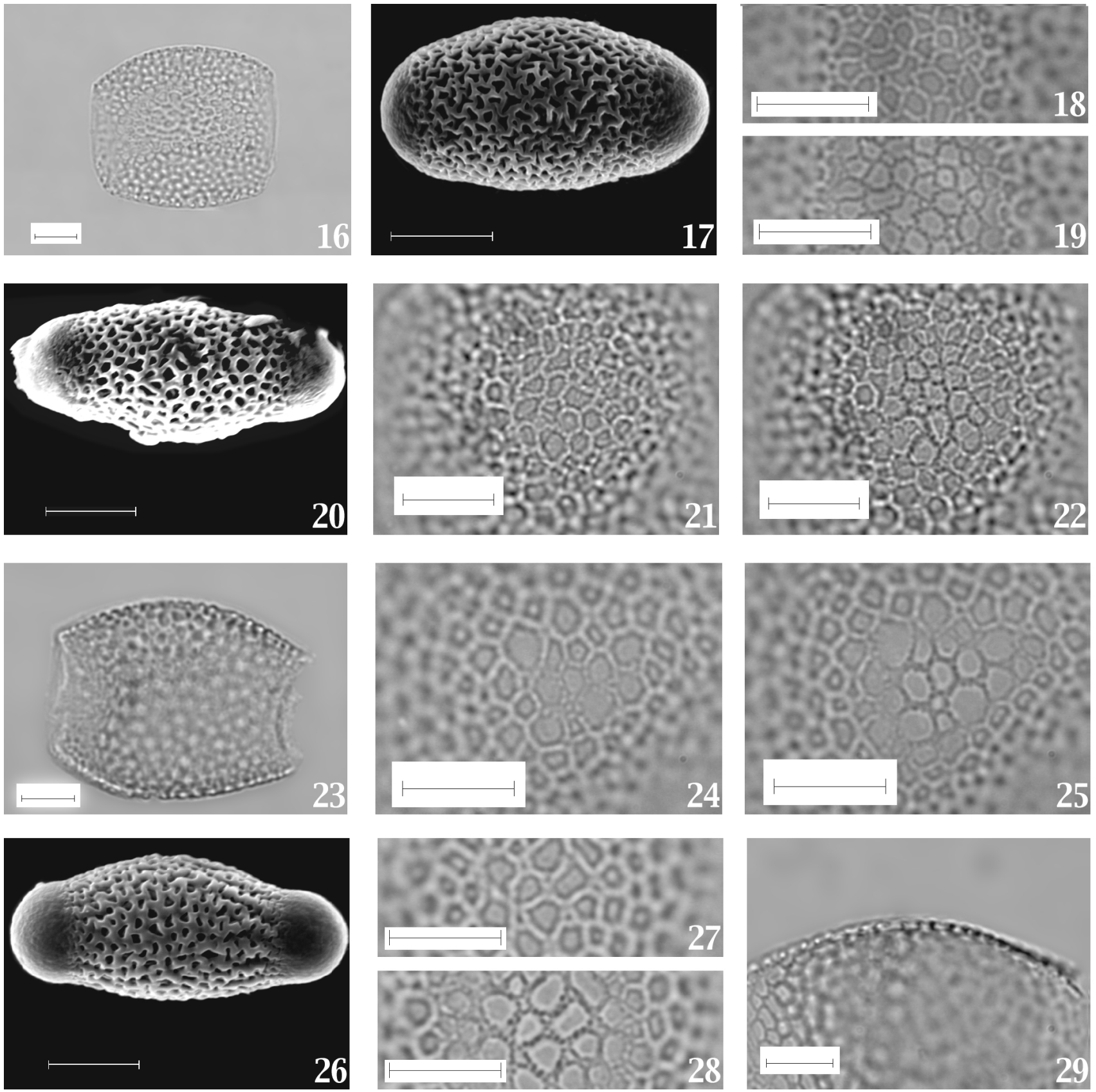

Figuras 16-19. Nidularium angustibracteatum Leme. 16. Vista equatorial do grão de pólen; 17. Eletromicrografia evidenciando aspecto geral do grão de pólen; 18-19. Análise de LO. Figuras 20-22. Nidularium meeanum Leme, Wand. \& Mollo. 20. Eletromicrografia evidenciando aspecto geral do grão de pólen; 21-22. Análise de LO. Figuras 23-25. Nidularium meeanum (M. Kirizawa 1521). 23. Vista polar do grão de pólen; 24-25. Análise de LO. Figuras 26-27. Nidularium procerum Lindm. 26. Eletromicrografia evidenciando aspecto geral do grão de pólen; 27-28. Análise de LO; 29. Corte óptico. Escala: $10 \mu \mathrm{m}$. 
ao subgênero Canistropsis, corroborando o que foi proposto por Pereira \& Leme (1986) e Leme (1998, 2000). Nidularium billbergioides destaca-se, dentro do subgênero Canistropsis, pela presença de muros duplicolumelados, enquanto as outras espécies do mesmo subgênero e do subgênero Nidularium apresentam muros simplescolumelados. Neoregelia laevis apresenta grãos de pólen semelhantes aos das espécies estudadas do subgênero Canistropsis, não só quanto ao padrão polínico mas, também, pela morfologia floral, onde as pétalas apresentam ápice agudo e não cuculado, sugerindo a possível proximidade entre esses dois táxons. Estes dados confirmam, ainda mais, a provável afinidade entre Neoregelia e Nidularium subgênero Canistropsis e levantam dúvidas quanto à posição taxonômica de Canistropsis: se um subgênero de Nidularium, um subgênero de Neoregelia, como proposto por Mez (1934-1935), ou um gênero à parte, como proposto por Leme (1998; 2000). Entretanto, pela pouca representatividade de material estudado e pela complexidade do problema, optou-se por manter Canistropsis como subgênero de Nidularium, uma vez que só com a revisão do gênero Neoregelia será possível definir melhor a circunscrição desses dois táxons, muito relacionados e com diferentes propostas de posicionamento taxonômico.

\section{Agradecimentos}

As autoras agradecem ao Dr. Fábio de Barros, do Instituto de Botânica, bem como aos assessores da Acta Botanica Brasilica, pelas sugestões apresentadas.

\section{Referências bibliográficas}

Ehler, N. \& Schill, R. 1973. Die Pollenmorphologie der Bromeliaceae. Pollen et Spores 15(1): 13-45.

Erdtman, G. \& Praglowski, K. 1974. A note on pollen morphology. In: L.B. Smith \& R.J. Downs (eds.). Flora Neotropica 14(1): 28-33.
Halbritter, H. 1992. Morphologie und Systematische Bedeutung des Pollens der Bromeliaceae. Grana 31: 197-212.

Halbritter, H. \& Till, W. 1998. Morfologia polínica do Complexo Nidularióde. In: M.V. Pereira (ed.). Bromélias da Mata Atlântica. Rio de Janeiro, Salamandra.

Leme, E.M.C. 1998. Canistropsis. In: M.V. Pereira (ed.). Bromélias da Mata Atlântica. Rio de Janeiro, Salamandra.

Leme, E.M.C. 2000. Nidularium. In: M.V. Pereira \& A. Jakobsson (eds.). Bromélias da Mata Atlântica. Rio de Janeiro, Sextante Artes.

Luther, H.E. \& Sieff, E. 1998. An alphabetical list of Bromeliad binnomials. Oregon, The Bromeliad Society.

Mez, C. 1891-1894. Bromeliaceae. In: C.F.P. Martius; A.G. Eichler \& I. Urban (eds.). Flora Brasiliensis... Monachii, Lipsiae, 3(3): 173-634, t. 51-114.

Mez, C. 1896. Bromeliaceae. In: H.G.A. Engler. Monographiae Phanerogamarum Prodromi... Paris, 9: 1-990.

Mez, C. 1934-1935. Bromeliaceae. In: H.G.A. Engler. Das Pflanzenreich. Stuttgart, Heft 100, 4(32): 1-667.

Pereira, E. \& Leme, E.M.C. 1986. Contribuição ao estudo do gênero Nidularium (Bromeliaceae) - Parte I - Subgênero Canistropsis. Bradea 4(32): 219-254.

Punt, W.; Blackmore, S.; Nilsson, S. \& Le Thomas, A. 1999. Glossary of pollen and spore terminology. http:/ www.biol.run.nl/-palaeo/glossary/glos-int.htm [acesso em 18/04/1999].

Raynal, A. \& Raynal, J. 1971. Une technique de préparation des grains de pollen fragiles. Adansonia 11(1): 77-79.

Reistma, T. 1969. Size modification of recent pollen grains unter different tratments. Review of Paleobotany and Palynology 9: 175-202.

Smith, L.B. \& Downs, R.J. 1979. Bromelioideae (Bromeliaceae). Flora Neotropica 14(3): 1493-2141.

Tardivo, R.C. \& Rodrigues, W.A. 1998. Pólen e estigma das espécies de Nidularium Leme e Cansitrum E. Morren (Bromeliaceae) ocorrentes no Estado do Paraná. Biotemas 11(1): 7-16.

Vieira, S. 1981. Introdução à Bioestatística. Rio de Janeiro, Campus.

Wanderley, M.G.L. \& Melhem, T.S. 1991. Flora Polínica da Reserva do Parque Estadual das Fontes do Ipiranga Família 178- Bromeliaceae. Hoehnea 18(1): 5-42.

Wanderley, M.G.L. \& Moreira, B.A. 2000. Notas taxonômicas sobre Nidularium Lem. e Wittrockia Lindm. (Bromelioideae, Bromeliaceae). Acta Botanica Brasilica 14(1): 1-9. 